\title{
Mineralization versus fermentation: evidence for two distinct anaerobic bacterial degradation pathways for dichloromethane
}

\author{
Gao Chen ${ }^{1,2} \cdot$ Alexander R. Fisch $^{3} \cdot$ Caleb M. Gibson $^{3,9} \cdot$ E. Erin Mack ${ }^{4}$ Edward S. Seger ${ }^{5}$ Shawn R. Campagna ${ }^{3}$. \\ Frank E. Löffler $\mathbb{B}^{1,2,6,7,8}$
}

Received: 18 July 2019 / Revised: 11 December 2019 / Accepted: 17 December 2019 / Published online: 6 January 2020

(c) The Author(s), under exclusive licence to International Society for Microbial Ecology 2020

\begin{abstract}
Dichloromethane (DCM) is an anthropogenic pollutant with ozone destruction potential that is also formed naturally. Under anoxic conditions, fermentation of DCM to acetate and formate has been reported in axenic culture Dehalobacterium formicoaceticum, and to acetate, $\mathrm{H}_{2}$ and $\mathrm{CO}_{2}$ in mixed culture $\mathrm{RM}$, which harbors the DCM degrader 'Candidatus Dichloromethanomonas elyunquensis'. RM cultures produced $28.1 \pm 2.3 \mu \mathrm{mol}$ of acetate from $155.6 \pm 9.3 \mu \mathrm{mol}$ DCM, far less than the one third (i.e., about $51.9 \mu \mathrm{mol}$ ) predicted based on the assumed fermentation model, and observed in cultures of Dehalobacterium formicoaceticum. Temporal metabolite analyses using gas chromatography-mass spectrometry (GCMS) and nuclear magnetic resonance (NMR) spectroscopy revealed that no ${ }^{13} \mathrm{C}$-labeled acetate was formed in ${ }^{13} \mathrm{C}$-DCMgrown RM cultures, indicating acetate was not a direct product of DCM metabolism. The data were reconciled with DCM mineralization and $\mathrm{H}_{2}$ consumption via $\mathrm{CO}_{2}$ reduction to acetate and methane by homoacetogenic and methanogenic partner populations, respectively. In contrast, Dehalobacterium formicoaceticum produced ${ }^{13} \mathrm{C}$-labeled acetate and formate from ${ }^{13} \mathrm{C}-\mathrm{DCM}$, consistent with a fermentation pathway. Free energy change calculations predicted that organisms with the mineralization pathway are the dominant DCM consumers in environments with $\mathrm{H}_{2}<100 \mathrm{ppmv}$. These findings have implications for carbon and electron flow in environments where DCM is introduced through natural production processes or anthropogenic activities.
\end{abstract}

Supplementary information The online version of this article (https:// doi.org/10.1038/s41396-019-0579-5) contains supplementary material, which is available to authorized users.

\section{Gao Chen}

gchen16@utk.edu

$\triangle$ Frank E. Löffler

frank.loeffler@utk.edu

1 Center for Environmental Biotechnology, University of Tennessee, Knoxville, TN 37996, USA

2 Department of Civil and Environmental Engineering, University of Tennessee, Knoxville, TN 37996, USA

3 Department of Chemistry, University of Tennessee, Knoxville, TN 37996, USA

4 Corteva Environmental Remediation, Corteva Agriscience, Wilmington, DE 19805, USA

\section{Introduction}

Substantial amounts of dichloromethane (DCM) exist in the environment due to anthropogenic activities and natural formation [1-4]. The total amount of DCM produced by various sources (e.g., industry, biomass combustion, biotic formation in oceans and terrestrial ecosystems, abiotic

5 Chemours Corporate Remediation Group, The Chemours Company, Wilmington, DE 19899, USA

6 Department of Microbiology, University of Tennessee, Knoxville, TN 37996, USA

7 Department of Biosystems Engineering \& Soil Science, University of Tennessee, Knoxville, TN 37996, USA

8 University of Tennessee and Oak Ridge National Laboratory (UTORNL), Joint Institute for Biological Sciences (JIBS) and Biosciences Division, Oak Ridge National Laboratory, Oak Ridge, TN 37831, USA

9 Present address: Department of Chemistry, West Virginia Wesleyan College, Buckhannon, WV 26201, USA 
formation) exceeds 900 gigagrams per year $\left(\mathrm{Gg} \mathrm{y}^{-1}\right)$ [3]. DCM emissions from global coastal oceans and tropical terrestrial mangrove forests were estimated at $68 \mathrm{Gg} \mathrm{y}^{-1}$ and $2-3 \mathrm{Gg} \mathrm{y}^{-1}$, respectively $[4,5]$. Of note, the actual amount of DCM formed in these environments must be substantially higher because a sink term for DCM (i.e., consumption by microorganisms) has not been considered. The analysis of air samples collected worldwide revealed that DCM concentrations in the atmosphere have shown a rapid increase of $38-69 \%$ over the last decade $[6,7]$.

DCM is of concern because it is a toxic groundwater contaminant, and also contributes to stratospheric ozone destruction $[8,9]$. DCM can be degraded by aerobes and facultative anaerobes harboring glutathione-dependent DCM dehalogenases [10, 11]. Compared with aerobic DCM degradation, the fate of DCM under strictly anoxic conditions remains poorly understood. Anaerobic degradation of DCM by mixed cultures was observed under methanogenic, acetogenic, and fermentation conditions, where DCM degradation was associated with methane and/or acetate production [12-16]. To date, Dehalobacterium formicoaceticum strain DMC of the Peptococcaceae family is the only described isolate capable of utilizing DCM as the sole energy source under anoxic conditions. During growth with DCM, this culture generates acetate and formate in a molar ratio of $1: 2$ consistent with a fermentation pathway (i.e., an internally balanced oxidation-reduction reaction yielding acetate as reduced and formate as oxidized products) [17, 18]. Cell-free crude extracts of $D$. formicoaceticum catalyzed the conversion of DCM to methylene-tetrahydrofolate $\left(\mathrm{CH}_{2}=\mathrm{THF}\right)$, and the activities of most of the Wood-Ljungdahl pathway enzymes were detected in in vitro enzyme assays [18]. Based on the physiology of $D$. formicoaceticum and enzymatic studies, it was proposed that DCM was dechlorinated, converted to $\mathrm{CH}_{2}=\mathrm{THF}$, and metabolized via the Wood-Ljungdahl pathway. Disproportionation of $\mathrm{CH}_{2}=\mathrm{THF}$ with two thirds being oxidized to formate generating reducing equivalents (i.e., $[\mathrm{H}]$ ) and one third (together with one $\mathrm{CO}_{2}$ ) being reduced to acetate matched the observed product pattern [18].

Culture RM was enriched from pristine freshwater sediment and degrades DCM under anoxic conditions generating biomass, inorganic chloride, methane, and acetate as end products [15]. Physiological, phylogenetic, and metagenomic analyses identified the specific DCM-degrading bacterium in culture RM as 'Candidatus Dichloromethanomonas elyunquensis', which represents a new genus and species within the family of Peptococcaceae [19]. The complete Wood-Ljungdahl pathway is encoded on the genomes of both DCM-degrading bacteria, and all the associated proteins have been detected in the proteome during growth with DCM [20-22], supporting the hypothesis that DCM is metabolized via the Wood-Ljungdahl pathway. DCM degradation by ' $\mathrm{Ca}$. Dichloromethanomonas elyunquensis' generates $\mathrm{H}_{2}$, and exogenously amended $\mathrm{H}_{2}$ impeded DCM degradation, which suggested the dependence of this organism on $\mathrm{H}_{2}$-consuming partner populations [23]. Consistent with this hypothesis, $16 \mathrm{~S}$ rRNA gene amplicon sequencing-based microbial community analysis revealed that, in addition to the dominant population ' $\mathrm{Ca}$. Dichloromethanomonas elyunquensis', culture RM grown with DCM also harbored populations belonging to the genera Acetobacterium and Methanospirillum, with relative abundances of around $1.4 \%$ and $7.1 \%$, respectively [23]. In contrast, $D$. formicoaceticum does not produce $\mathrm{H}_{2}$ during DCM degradation and does not rely on $\mathrm{H}_{2}$-scavenging microorganisms. Intriguingly, dual carbon (C) and chlorine $(\mathrm{Cl})$ isotope fractionation analysis revealed distinct dual element $\mathrm{C}-\mathrm{Cl}$ isotope correlations during anaerobic DCM degradation by D. formicoaceticum and culture RM, suggestive of mechanistically distinct steps in the DCM degradation pathways employed by the two bacterial populations [24]. A proteogenomic study revealed the expression of reductive dehalogenases exclusively during DCM metabolism by ' $\mathrm{Ca}$. Dichloromethanomonas elyunquensis', whereas $D$. formicoaceticum does not possess reductive dehalogenase genes, lending further support to the hypothesis of distinct modifications that channel DCM into the Wood-Ljungdahl pathway [22]. The present study employed stable carbon isotope labeling and metabolite analyses to compare and elucidate anaerobic DCM metabolism in the axenic culture $D$. formicoaceticum and the mixed culture RM harboring ' $\mathrm{Ca}$. Dichloromethanomonas elyunquensis'.

\section{Materials and methods}

\section{Chemicals}

DCM (purity >99.95\%) was purchased from Acros Organics (Thermo Fisher Scientific, Fair Lawn, NJ, USA). ${ }^{13} \mathrm{C}$-labeled DCM (99 atom $\%{ }^{13} \mathrm{C}$ ) was obtained from two sources: Cambridge Isotope Laboratories Inc. (Andover, MA, USA) and Sigma-Aldrich (St. Louis, MO, USA). HPLC grade propanol, pyridine, propyl chloroformate $(\mathrm{PCF})$, hexane, and $\left[2-{ }^{13} \mathrm{C}\right]$-acetate $\left(99\right.$ atom $\left.\%{ }^{13} \mathrm{C}\right)$ were purchased from Sigma-Aldrich. All other chemicals used were analytical reagent grade or higher, unless otherwise specified.

\section{Microorganisms and cultivation}

Culture RM, harboring DCM-degrading ' $\mathrm{Ca}$. Dichloromethanomonas elyunquensis', was enriched from freshwater sediment [15]. After establishing the enrichment culture, culture RM was maintained in the laboratory by repeated transfers to defined, completely synthetic basal salt medium with DCM as the sole electron donor. $D$. 
formicoaceticum was obtained from American Type Culture Collection (ATCC 700118). Both D. formicoaceticum and culture RM were cultivated in bicarbonate-buffered $(30 \mathrm{mM}$, $\mathrm{pH}$ 7.3) anoxic basal salt medium reduced with $\mathrm{Na}_{2} \mathrm{~S}(0.2$ $\mathrm{mM})$ and L-cysteine $(0.2 \mathrm{mM})$ and the routine cultivation was performed as described [23, 25]. Briefly, cultivation occurred in $160-\mathrm{mL}$ glass serum bottles containing $100 \mathrm{~mL}$ of medium. The vessels were sealed with black butyl rubber stoppers (Bellco Glass, Vineland, NJ, USA) under a headspace of $\mathrm{N}_{2} / \mathrm{CO}_{2}(80 / 20, \mathrm{vol} / \mathrm{vol})$ and $5-10 \mu \mathrm{L}$ neat DCM (78-156 $\mu \mathrm{mol})$ was provided as the sole energy source prior to inoculation from a DCM-grown culture (5\%, vol/vol). To inhibit methanogenesis, $2 \mathrm{mM}$ 2-bromoethanesulfonate (BES) was added to the medium. All culture vessels were incubated at $30^{\circ} \mathrm{C}$ in the dark without agitation. To investigate the requirement of bicarbonate/ $\mathrm{CO}_{2}$, bicarbonate buffer was substituted by HEPES buffer ( $30 \mathrm{mM}, \mathrm{pH} 7.3)$ and the medium was flushed with $\mathrm{N}_{2}$ gas instead of a $\mathrm{N}_{2} /$ $\mathrm{CO}_{2}$ gas mixture. Control incubations with the HEPESbuffered medium received $10 \mathrm{mM}$ bicarbonate from an anoxic, sterilized $1 \mathrm{M}$ bicarbonate stock solution.

\section{DNA extraction and quantitative real-time polymerase chain reaction (qPCR)}

16S rRNA gene-targeted qPCR assays were used to monitor growth of the DCM degraders, i.e., D. formicoaceticum and ' $\mathrm{Ca}$. Dichloromethanomonas elyunquensis', in cultures grown with DCM as the sole energy source. For DNA extraction, $5 \mathrm{~mL}$ of culture suspension samples were collected and filtered onto $0.22 \mu \mathrm{m}$ Durapore membranes (Millipore, Cork, Ireland). DNA was extracted using the DNeasy PowerSoil DNA isolation kit (Qiagen, Hilden, Germany) following the manufacturer's protocol. qPCR primers (Dforq1205F, 5'-CACCACGAAAGTTGGCAACA-3'; and Dforq1265R, 5'-TTCGGCGACTGCTTCCTT-3') and a probe (Dforq1229-MGB, 5'-FAM-AAGTCGATGAGCGA ACC-MGB-3') were used to specifically target the $16 \mathrm{~S}$ rRNA gene of $D$. formicoaceticum. qPCR primers and a probe targeting $16 \mathrm{~S}$ rRNA gene of ' $\mathrm{Ca}$. Dichloromethanomonas elyunquensis' have been reported [19]. qPCR followed published protocols $[19,26]$ and was conducted using an ABI ViiA7 real-time PCR system (Life Technologies) and data processed with ViiA7 Software (Life Technologies).

\section{Analytical procedures}

DCM and methane were measured by manual headspace injections $(0.1 \mathrm{~mL})$ into an Agilent $7890 \mathrm{~A}$ gas chromatograph (GC) (Santa Clara, CA, USA) equipped with a DB624 column $(60 \mathrm{~m}$ length, $0.32 \mathrm{~mm}$ i.d., $1.8 \mathrm{~mm}$ film thickness) and a flame ionization detector (FID). The GC inlet was maintained at $200^{\circ} \mathrm{C}$, the $\mathrm{GC}$ oven temperature was kept at $60{ }^{\circ} \mathrm{C}$ for $2 \mathrm{~min}$ followed by an increase to $200{ }^{\circ} \mathrm{C}$ at a ramping rate of $25^{\circ} \mathrm{C} \mathrm{min}^{-1}$, and the FID detector was operated at $300{ }^{\circ} \mathrm{C}$. Acetate and formate were measured using an Agilent 1200 series high-performance liquid chromatography (HPLC) system equipped with an Aminex HPX-87H column (Bio-Rad, Hercules, CA, USA) and a UV detector set to $210 \mathrm{~nm}$. The separation occurred at a column temperature of $30^{\circ} \mathrm{C}$ over a $25 \mathrm{~min}$ period, and the eluent $\left(4 \mathrm{mM} \mathrm{H}_{2} \mathrm{SO}_{4}\right)$ was delivered isocratically at a rate of $0.6 \mathrm{~mL} \mathrm{~min}^{-1}$.

For ${ }^{13} \mathrm{C}$ labeled acetate analysis, a volume of $1000 \mu \mathrm{L}$ culture sample was taken using a $\mathrm{N}_{2}$-flushed syringe and centrifuged to remove cells. The derivatization of acetate to propyl acetate was performed as described [27]. In brief, $800 \mu \mathrm{L}$ sample was mixed with $500 \mu \mathrm{L}$ of propanol/pyridine mixture solvent (3:2, vol:vol) in a glass vial and $100 \mu \mathrm{L}$ of PCF was subsequently added. The resulting mixture was vortexed briefly and the derivatization reaction proceeded in an ultrasonic water bath (Fisher Scientific, Pittsburg, PA, USA) for $1 \mathrm{~min}$. After derivatization, the organic compounds were extracted with $300 \mu \mathrm{L}$ of hexane, and the hexane extracts were analyzed with GC-MS. GC-MS analysis was performed using an Agilent 7890A gas chromatograph (Santa Clara, CA, USA) equipped with a DB-624 column ( $60 \mathrm{~m}$ length, $0.32 \mathrm{~mm}$ i.d., $1.8 \mathrm{~mm}$ film thickness) and an Agilent 5975C inert XL MSD with a Triple-axis detector (Santa Clara, CA, USA). The GC inlet was maintained at $200{ }^{\circ} \mathrm{C}$, and the GC oven temperature was kept at $60^{\circ} \mathrm{C}$ for $2 \mathrm{~min}$ followed by an increase to $90^{\circ} \mathrm{C}$ at a ramping rate of $5^{\circ} \mathrm{C} \mathrm{min}^{-1}$ and then another increase to 200 ${ }^{\circ} \mathrm{C}$ at a rate of $25^{\circ} \mathrm{C} \mathrm{min}^{-1}$.

\section{${ }^{1} \mathrm{H}$ and ${ }^{13} \mathrm{C}$ NMR spectroscopy analyses}

All NMR spectra were acquired using a Varian VNMRS $600 \mathrm{MHz}$ NMR spectrometer equipped with a 5-mm inverse-proton (HX) triple resonance probe. The NMR tube used was a custom order from New Era Enterprises, Inc. featuring an outer 5-mm diameter tube with a septum screw tip and a separate coaxial insertion tube with a cap. For NMR analysis, $600 \mu \mathrm{L}$ of culture sample was added into the outer NMR tube followed by insertion of the inner NMR tube containing $100 \mu \mathrm{L}$ of $\mathrm{D}_{2} \mathrm{O}$ with $9.2 \mathrm{mg}$ of internal standard 4,4-dimethyl-4-silapentane-1-sulfonic acid (DSS), and the NMR tube was sealed with a screw cap with a rubber O-ring. The experimental setup was conducted in a glove bag filled with argon gas to avoid any contact with oxygen. The culture RM sample was scanned for 27 days and scanning began once the labeled ${ }^{13} \mathrm{C}$-DCM had been injected into the outer tube. ${ }^{1} \mathrm{H}$ NMR and ${ }^{13} \mathrm{C}$ NMR spectra were taken over the time period with additional 2D spectra $\left({ }^{1} \mathrm{H}-{ }^{13} \mathrm{C}\right)$ heteronuclear single quantum 
coherence spectroscopy (HSQC), ${ }^{1} \mathrm{H}-{ }^{13} \mathrm{C}$ heteronuclear multiple bond correlation (HMBC), ${ }^{1} \mathrm{H}-{ }^{1} \mathrm{H}$ homonuclear correlation spectroscopy (COSY) and ${ }^{13} \mathrm{C}-{ }^{13} \mathrm{C}$ distortionless enhancement of polarization transfer (DEPT) taken for metabolite identification. The axenic culture $D$. formicoaceticum grown with ${ }^{13} \mathrm{C}-\mathrm{DCM}$ was scanned with both ${ }^{1} \mathrm{H}$ NMR and ${ }^{13} \mathrm{C}$ NMR, with additional ${ }^{1} \mathrm{H}-{ }^{13} \mathrm{C}$ HSQC for peak confirmation.

\section{Results and discussion}

\section{Stoichiometry of DCM degradation by culture RM}

In axenic cultures of $D$. formicoaceticum, DCM degradation supported growth and the organism's 16S rRNA gene copy number increased from $4.82 \times 10^{6} \pm 1.30 \times 10^{5}$ to $6.98 \times$ $10^{8} \pm 5.26 \times 10^{7}$ (Supplementary Information, Fig. S1). A yield of $3.66 \times 10^{7} \pm 2.79 \times 10^{6}$ cells per $\mu$ mol of DCM consumed was calculated for $D$. formicoaceticum, which is similar to the reported value of $5.25 \times 10^{7} \pm 1.0 \times 10^{7}$ cells per $\mu \mathrm{mol}$ of DCM for ' $\mathrm{Ca}$. Dichloromethanomonas elyunquensis' in culture RM [19]. In DCM-grown RM cultures without amendment of the methanogenesis inhibitor BES, methane and acetate were produced as metabolic end products (Fig. 1a). The amount of $155.6 \pm 9.3 \mu \mathrm{mol}$ of DCM was completely degraded over a 28-day incubation period generating $42.5 \pm 7.7 \mu \mathrm{mol}$ of methane and $28.1 \pm 2.3 \mu \mathrm{mol}$ of acetate per bottle (Fig. 1a). The addition of $2 \mathrm{mM}$ BES completely abolished methane production but did not prevent DCM degradation (Fig. 1b). In BES-amended cultures, DCM $(147.1 \pm 4.3 \mu \mathrm{mol})$ was completely degraded within 40 days of incubation generating $71.4 \pm 3.2 \mu \mathrm{mol}$ of acetate per bottle (Fig. 1b). Stoichiometric calculations determined an electron recovery of approximately $97 \%$ and $91 \%$ with and without the amendment of BES, respectively, indicating that the majority of electrons released from DCM oxidation were recovered in methane and/or acetate (Table 1). Since DCM degradation occurred in BES-amended cultures without methane formation (Fig. 1b), the stepwise reductive dechlorination of DCM to chloromethane $\left(\mathrm{CH}_{3} \mathrm{Cl}\right)$ and then to methane $\left(\mathrm{CH}_{4}\right)$, a pathway typically observed during reductive dechlorination of chlorinated ethenes [28], can be excluded. This conclusion is consistent with the absence of chloromethane as an intermediate in cultures grown with DCM [23].

\section{Refuting acetate as a direct product of anaerobic DCM degradation by culture RM}

DCM degradation by the axenic culture $D$. formicoaceticum yielded acetate and formate as terminal products in a molar ratio of approximately $1: 2[17,18]$. Therefore, it was proposed that DCM was fermented to acetate and formate using the Wood-Ljungdahl pathway according to Eq. (1) $[17,18]$.

$$
\begin{gathered}
3 \mathrm{CH}_{2} \mathrm{Cl}_{2}+4 \mathrm{H}_{2} \mathrm{O}+\mathrm{CO}_{2} \rightarrow 2 \mathrm{HCOO}^{-}+\mathrm{CH}_{3} \mathrm{COO}^{-} \\
+9 \mathrm{H}^{+}+6 \mathrm{Cl}^{-} \Delta G^{\circ \prime}=-226 \mathrm{~kJ} \mathrm{~mol}^{-1}
\end{gathered}
$$

Based on the observation that $\mathrm{H}_{2}$ is an intermediate and acetate is an end product of DCM metabolism in culture $\mathrm{RM}$, it was proposed that ' $\mathrm{Ca}$. Dichloromethanomonas elyunquensis' fermented DCM to acetate, $\mathrm{CO}_{2}$, and $\mathrm{H}_{2}$ according to Eq. (2) [23].

$$
\begin{aligned}
3 \mathrm{CH}_{2} \mathrm{Cl}_{2} & +4 \mathrm{H}_{2} \mathrm{O} \rightarrow 2 \mathrm{H}_{2}+\mathrm{CO}_{2}+\mathrm{CH}_{3} \mathrm{COO}^{-}+7 \mathrm{H}^{+} \\
& +6 \mathrm{Cl}^{-} \Delta G^{\circ \prime}=-228 \mathrm{~kJ} \mathrm{~mol}^{-1}
\end{aligned}
$$

In both of the hypothetical DCM fermentation pathways (Eqs. (1) and (2)), acetate is assumed to be a direct product of DCM metabolism, and the molar ratio of acetate
Fig. 1 DCM degradation by culture RM and associated product formation. (a) DCM degradation and methane and acetate formation. (b) In presence of the methanogenesis inhibitor BES, methane production was abolished, and acetate was the sole product of DCM metabolism by RM cultures. Data shown represent means \pm standard deviation $(n=$ 3 ), and error bars represent standard deviations.
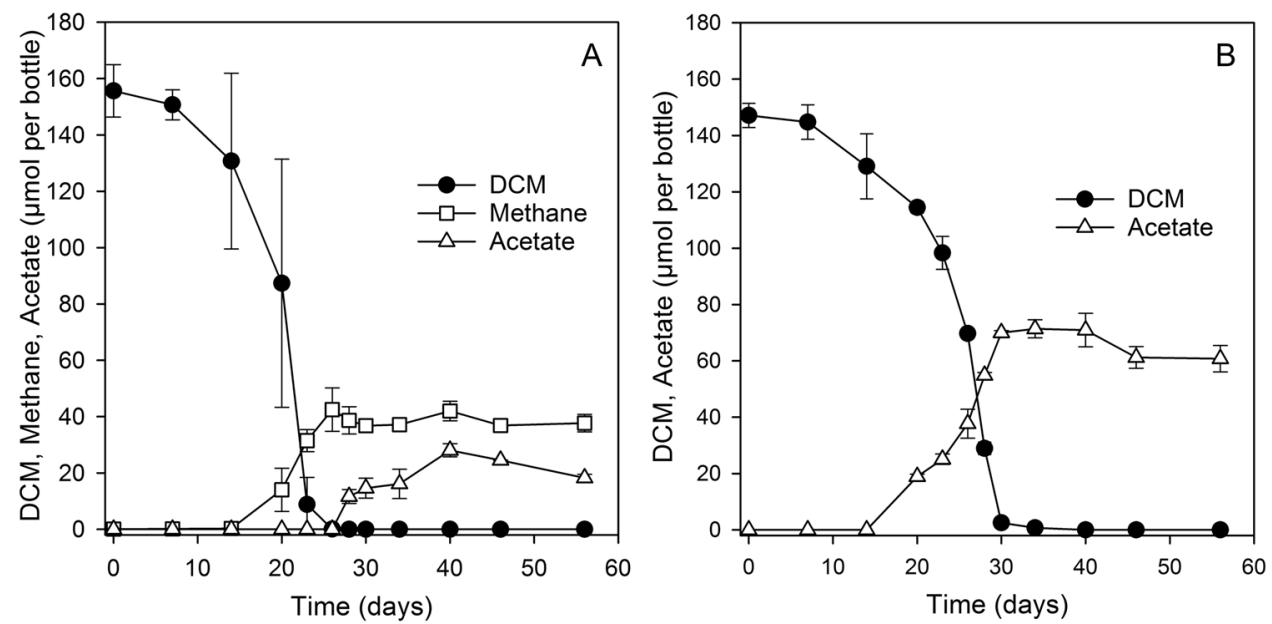
Table 1 Stoichiometry of substrate consumption and product formation, and calculation of electron recovery in RM cultures grown with DCM as electron donor with or without methanogenesis inhibitor BES as depicted in Fig. 1.

\begin{tabular}{|c|c|c|c|c|c|c|}
\hline \multirow[t]{2}{*}{ Experiments } & \multicolumn{2}{|c|}{ Substrate ( $\mu$ mol per bottle) } & \multicolumn{3}{|c|}{ Products ( $\mu$ mol per bottle) } & \multirow{2}{*}{$\begin{array}{l}\text { Electron } \\
\text { balance }(\%)\end{array}$} \\
\hline & DCM & $\begin{array}{l}\text { Available } \\
\text { electrons }\end{array}$ & Methane & Acetate & $\begin{array}{l}\text { Recovered } \\
\text { electrons }\end{array}$ & \\
\hline DCM & $155.6 \pm 9.3$ & $622.4 \pm 37.2$ & $42.5 \pm 7.7$ & $28.1 \pm 2.3$ & 564.8 & 90.7 \\
\hline $\mathrm{DCM}+\mathrm{BES}$ & $147.1 \pm 4.3$ & $588.5 \pm 17.2$ & 0.0 & $71.4 \pm 3.2$ & 571.4 & 97.1 \\
\hline
\end{tabular}

Electrons available from substrate oxidation were calculated according to the following equations: DCM oxidation: $\mathrm{CH}_{2} \mathrm{Cl}_{2}+2 \mathrm{H}_{2} \mathrm{O} \rightarrow \mathrm{CO}_{2}+2 \mathrm{Cl}^{-}+6 \mathrm{H}^{+}+4 \mathrm{e}^{-}$. The recovered electrons were calculated according to the following equations: (1) $\mathrm{CO}_{2}+8 \mathrm{H}^{+}+8 \mathrm{e}^{-} \rightarrow \mathrm{CH}_{4}+2 \mathrm{H}_{2} \mathrm{O}$; (2) $2 \mathrm{CO}_{2}+7 \mathrm{H}^{+}+8 \mathrm{e}^{-} \rightarrow$ $\mathrm{CH}_{3} \mathrm{COO}^{-}+2 \mathrm{H}_{2} \mathrm{O}$. Electron balance $(\%)=\frac{\text { Recovered electrons }}{\text { Available electrons }} \times 100(\%)$. All calculations used data generated from triplicate incubations. versus DCM should be 1:3. Acetate was a dead-end product in axenic cultures of $D$. formicoaceticum and also in mixed culture RM, which did not produce methane from acetate.

16S rRNA gene amplicon sequencing applied to DCMgrown culture RM revealed the presence of Acetobacterium spp. [23]. These homoacetogens exclusively produce acetyl$\mathrm{CoA}$ (and from that acetate as the end product) from reducing two molecules of $\mathrm{CO}_{2}$ with $\mathrm{H}_{2}$ as an electron donor through the reactions of the Wood-Ljungdahl pathway [29]. According to Eq. (2), DCM undergoes a fermentation reaction leading to the formation of $\mathrm{H}_{2}$, which is consumed in $\mathrm{H}_{2} / \mathrm{CO}_{2}$ reductive acetogenesis by Acetobacterium populations. Assuming ' $\mathrm{Ca}$. Dichloromethanomonas elyunquensis' would catalyze DCM fermentation according to Eq. (2) and Acetobacterium spp. in culture RM utilize the $\mathrm{H}_{2}$ generated during DCM degradation and available $\mathrm{CO}_{2}$ to produce acetate, the measured amount of acetate should be more than one third of the initially amended amount of DCM. However, RM cultures that received 155.6 $\pm 9.3 \mu \mathrm{mol}$ of DCM without BES amendment only produced $28.1 \pm 2.3$ $\mu$ mol per bottle of acetate (Fig. 1a, and Table 1). This amount was far less than the theoretical amount of acetate expected in culture RM based on Eq. (2) (viz., at least one third of DCM should be recovered as acetate if DCM is metabolized according to Eq. (2)), thus raising the question whether acetate was a direct product of DCM metabolism by 'Ca. Dichloromethanomonas elyunquensis'. Careful monitoring of DCM consumption and acetate formation in RM cultures demonstrated that acetate production started after DCM had been depleted (Fig. 1a). These observations imply that acetate detected in culture RM may not be a direct product of DCM metabolism but the result of homoacetogenic bacteria (e.g., Acetobacterium) reducing $\mathrm{CO}_{2}$ with $\mathrm{H}_{2}$ as an electron donor.

To further explore the products directly derived from DCM degradation by ' $\mathrm{Ca}$. Dichloromethanomonas elyunquensis', stable carbon isotope labeled DCM $\left({ }^{13} \mathrm{CH}_{2} \mathrm{Cl}_{2}\right)$ was employed to trace product formation in culture RM. ${ }^{13} \mathrm{C}$-labeled DCM (99 atom $\%{ }^{13} \mathrm{C}$ ) was initially obtained from Cambridge Isotope Laboratories Inc.; however, several attempts to grow culture RM and D. formicoaceticum with this product failed. Careful examination of this commercial product using gas chromatography detected impurities, one of which co-eluted with chloroform. A prior study demonstrated that culture RM is sensitive to chloroform [30]. Inhibition of dechlorinators by impurities is not unprecedented and the presence of $0.4 \%$ $(\mathrm{mol} / \mathrm{mol})$ of chloroform in commercial cis-1,2-dichloroethene prevented reductive dechlorination by Dehalococcoides mccartyi strain 195 [31]. We then switched to a different supplier and both DCM-degrading cultures grew with ${ }^{13} \mathrm{C}$-labeled DCM (99 atom $\%{ }^{13} \mathrm{C}$ ) obtained from Sigma-Aldrich with similar lag times and degradation rates observed with unlabeled DCM.

Gas chromatography-mass spectrometry (GC-MS) analysis of an unlabeled acetate standard (measured as propyl acetate after derivatization) revealed three major characteristic ion fragments with mass-to-charge ratio $(\mathrm{m} / \mathrm{z})$ values of 43, 61, and 73 (Fig. 2a). RM cultures that received ${ }^{13} \mathrm{C}$ DCM or unlabeled DCM as the sole electron donor and 2 $\mathrm{mM}$ BES to inhibit methanogenesis produced acetate, but no methane, as metabolic end product. GC-MS analysis of the products formed in culture RM grown with ${ }^{13} \mathrm{C}$-DCM revealed that the three major ion fragments of propyl acetate had the same $\mathrm{m} / \mathrm{z}$ values as those of the unlabeled standard (i.e., $\mathrm{m} / \mathrm{z}$ values of 43,61 , and 73 ) indicating the acetate pool generated in culture RM was not ${ }^{13} \mathrm{C}$ labeled (Fig. 2b). This finding is consistent with the hypothesis that acetate in culture RM was not directly derived from DCM metabolism by ' $\mathrm{Ca}$. Dichloromethanomonas elyunquensis' but is a product of $\mathrm{H}_{2} / \mathrm{CO}_{2}$ reductive acetogenesis mediated by homoacetogens present in the mixed culture. In contrast, ${ }^{13} \mathrm{C}$-labeled acetate was detected in growth experiments with axenic culture $D$. formicoaceticum that received ${ }^{13} \mathrm{C}$-DCM as the sole substrate (Fig. 2c). When grown with ${ }^{13} \mathrm{C}$-DCM, the $\mathrm{m} / \mathrm{z}$ values of the three dominant ion fragments of derivatized acetate (i.e., propyl acetate) were one mass unit greater (i.e., $\mathrm{m} / \mathrm{z}$ values of 44,62 , and 74 ) than those of the unlabeled standard (Fig. 2c). The label incorporation demonstrated that acetate was a direct product of DCM metabolism by D. formicoaceticum, which is 

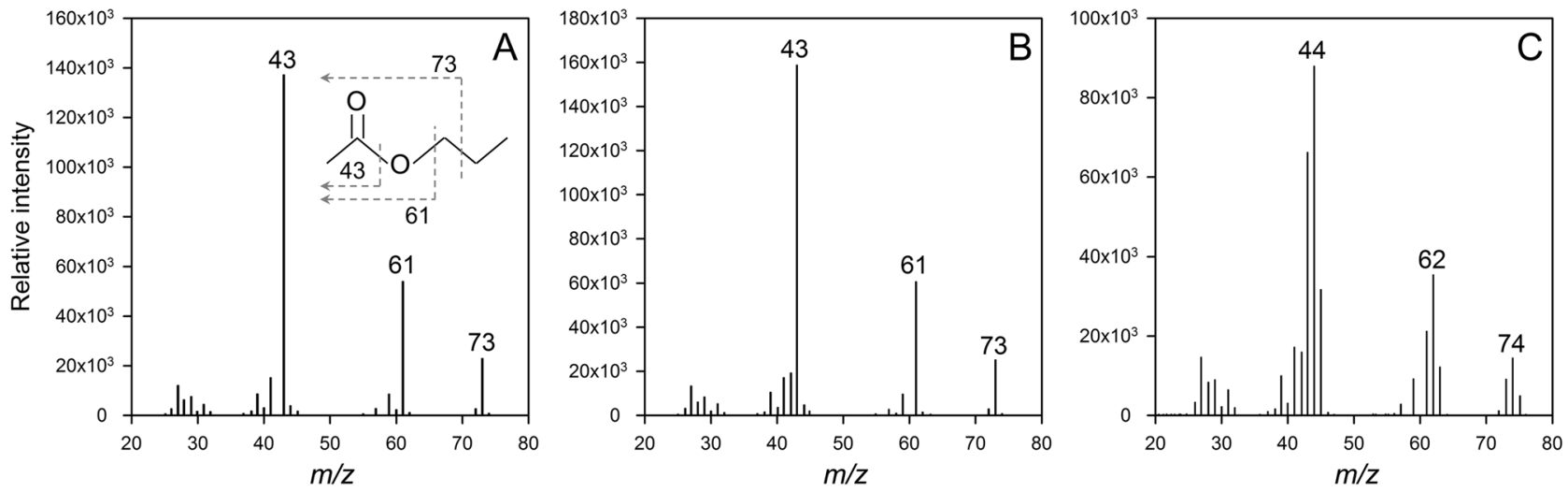

Fig. 2 Analysis of ${ }^{13} \mathbf{C}$-label in acetate produced in cultures metabolizing ${ }^{13} \mathbf{C}$-DCM. Mass spectra of propyl ester derivatives of an acetate standard (a). Panels B and C show the mass spectra of acetate propyl ester derivatives extracted from culture RM and from D. formicoaceticum supplemented with ${ }^{13} \mathrm{C}$-DCM as the sole electron donor, respectively. The identification of the acetate propyl ester in (b) and (c) is based on comparison of the GC retention time of $9.58 \mathrm{~min}$ of the derivatized acetate propyl ester standard.

consistent with the proposed fermentation pathway (Eq. (1)). In a previous study, ${ }^{13} \mathrm{C}$-labeled acetate was also detected in a DCM-fermenting mixed culture dominated by Dehalobacter populations during growth with ${ }^{13} \mathrm{C}-\mathrm{DCM}$, suggestive of fermentative DCM metabolism [32].

\section{Metabolite analysis of cultures grown with ${ }^{13} \mathrm{C}-\mathrm{DCM}$ using NMR spectroscopy}

${ }^{1} \mathrm{H}$ and ${ }^{13} \mathrm{C}$ NMR spectroscopy were employed for in vivo monitoring of metabolite formation in both cultures, i.e., in culture RM harboring ' $\mathrm{Ca}$. Dichloromethanomonas elyunquensis' and in axenic culture $D$. formicoaceticum, both grown with ${ }^{13} \mathrm{C}$-labeled DCM as the sole electron donor. In culture RM, ${ }^{1} \mathrm{H}$ NMR spectroscopy revealed two distinct peaks at chemical shift of $\delta 5.29 \mathrm{ppm}$ and $\delta 5.59 \mathrm{ppm}$, which corresponded to the two hydrogen $(\mathrm{H})$ atoms of ${ }^{13} \mathrm{C}$ DCM. In the ${ }^{13} \mathrm{C}$ NMR spectra, ${ }^{13} \mathrm{C}$-DCM showed a single peak at a chemical shift of $\delta 53 \mathrm{ppm}$. As shown in both ${ }^{1} \mathrm{H}$ and ${ }^{13} \mathrm{C}$ NMR spectra, the amended ${ }^{13} \mathrm{C}$-DCM was completely degraded by culture RM over a span of 11 days in the NMR tube (Fig. 3a). Concomitant with the degradation of ${ }^{13} \mathrm{C}$-DCM, ${ }^{13} \mathrm{C}$-labeled $\mathrm{CO}_{2}$ was formed in culture $\mathrm{RM}$ as revealed in the ${ }^{13} \mathrm{C}$ NMR spectra with a peak at a chemical shift of $\delta 125 \mathrm{ppm}$, suggesting DCM was oxidized to $\mathrm{CO}_{2}$ (Fig. 3a). Acetate and methane were detected by ${ }^{1} \mathrm{H}$ NMR with peaks at chemical shifts of $\delta 1.90 \mathrm{ppm}$ and $\delta$ $0.16 \mathrm{ppm}$, respectively; however, neither methane nor acetate was labeled with ${ }^{13} \mathrm{C}$ as evidenced by the absence of splitting and corresponding peaks in the ${ }^{13} \mathrm{C}$ NMR spectra (Fig. 3a).

The axenic culture $D$. formicoaceticum produced ${ }^{13} \mathrm{C}$ labeled acetate when grown with ${ }^{13} \mathrm{C}-\mathrm{DCM}$, and the ${ }^{13} \mathrm{C}$ label was found exclusively in the methyl group of acetate (i.e., $\left[2-{ }^{13} \mathrm{C}\right]$-acetate) as revealed in the ${ }^{13} \mathrm{C}$ NMR spectra with a peak at a chemical shift of $\delta 23 \mathrm{ppm}$ (Fig. 3b). There was no peak in ${ }^{13} \mathrm{C}$ NMR spectra at a chemical shift of $\delta$ $181 \mathrm{ppm}$, which would correspond to ${ }^{13} \mathrm{C}$-acetate with ${ }^{13} \mathrm{C}$ label in the carboxyl carbon (i.e., $\left[1-{ }^{13} \mathrm{C}\right]$-acetate) (Fig. 3b). ${ }^{1} \mathrm{H}$ NMR analysis revealed that in addition to $\left[2-{ }^{13} \mathrm{C}\right]-$ acetate (viz., the ${ }^{1} \mathrm{H}$ of $\left[2-{ }^{13} \mathrm{C}\right]$-acetate had two splitting peaks at chemical shifts of $\delta 2.01 \mathrm{ppm}$ and $\delta 1.80 \mathrm{ppm}$ ), a peak with a chemical shift at $\delta 1.90 \mathrm{ppm}$ in the ${ }^{1} \mathrm{H}$ NMR spectrum indicative of unlabeled acetate was also detected (Fig. 3b). The ${ }^{1} \mathrm{H}$ and ${ }^{13} \mathrm{C}$ NMR spectra of $\left[2-{ }^{13} \mathrm{C}\right]$-acetate and unlabeled acetate standards are provided in the Supplementary Information (SI, Fig. S2). The formation of unlabeled acetate might be attributed to carbon isotope exchange with the ambient unlabeled $\mathrm{CO}_{2}$ because of the reversibility of Wood-Ljungdahl pathway [33, 34]. In addition to $\left[2-{ }^{13} \mathrm{C}\right]$-acetate, ${ }^{13} \mathrm{C}$-formate was also formed in cultures of $D$. formicoaceticum when grown on ${ }^{13} \mathrm{C}$-DCM. ${ }^{13} \mathrm{C}$-formate showed a peak at the chemical shift of $\delta 171$ ppm on ${ }^{13} \mathrm{C}$ NMR and two splitting peaks at $\delta 8.59 \mathrm{ppm}$ and $\delta 8.27 \mathrm{ppm}$ in the ${ }^{1} \mathrm{H}$ NMR spectrum. Similar as acetate, unlabeled formate was also detected on ${ }^{1} \mathrm{H}$ NMR, which had a peak at a chemical shift of $\delta 8.44 \mathrm{ppm}$. In addition, ${ }^{13} \mathrm{C}$-labeled methanol and glycine were detected by ${ }^{1} \mathrm{H}$ and ${ }^{13} \mathrm{C}$ NMR spectroscopy and confirmed by ${ }^{1} \mathrm{H}_{-}{ }^{13} \mathrm{C}$ HSQC (Fig. 3b; and SI, Fig. S3), suggesting these compounds are formed during DCM metabolism by $D$. formicoaceticum. Similar to the ${ }^{1} \mathrm{H}$ NMR spectra of ${ }^{13} \mathrm{C}$-DCM, ${ }^{13} \mathrm{C}$-labeled acetate, formate, methanol, and glycine were all detected with two large side peaks on ${ }^{1} \mathrm{H}$ NMR caused by splitting due to the presence of a labeled ${ }^{13} \mathrm{C}$ atom in the molecules (Fig. 3b).

The detection of methanol in D. formicoaceticum cultures was consistent with a previous study suggesting methanol might be a byproduct of DCM metabolism by D. formicoaceticum [18]. Glycine can be synthesized 


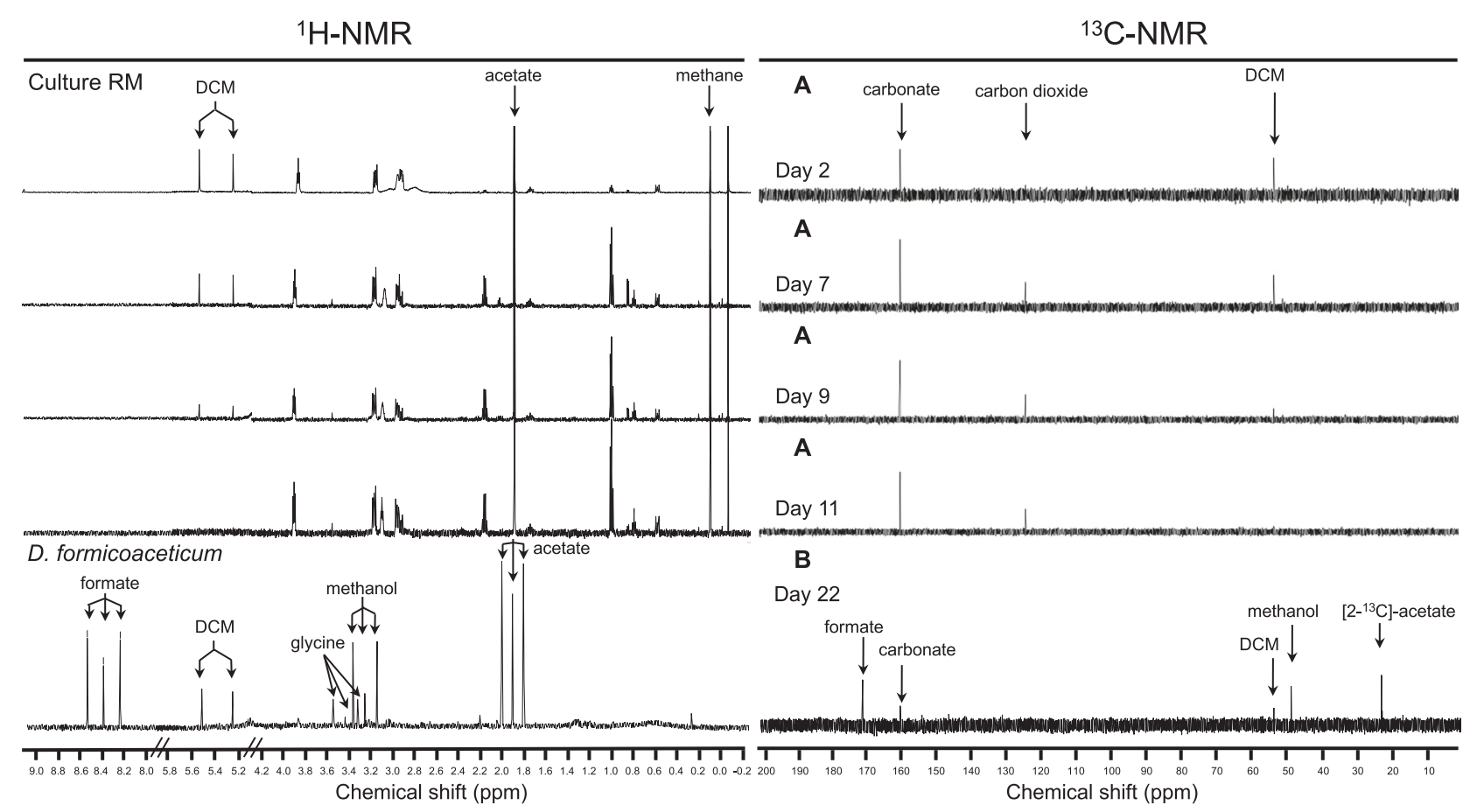

Fig. $3{ }^{1} \mathrm{H}$ NMR and ${ }^{13} \mathrm{C}$ NMR spectra comparing the degradation of ${ }^{13} \mathrm{C}$-DCM by culture RM (A panels) and $\mathrm{D}$. formicoaceticum (B panel) directly in glass NMR tubes. ${ }^{1} \mathrm{H}$ NMR and ${ }^{13} \mathrm{C}$ NMR spectra revealed that ${ }^{13} \mathrm{C}$-labeled acetate was only formed in culture $D$. formicoaceticum, but was absent in culture RM. Instead, ${ }^{13} \mathrm{C}$ NMR spectra showed that ${ }^{13} \mathrm{C}$-labeled $\mathrm{CO}_{2}$ was only detected in culture RM. Please see the main text for the detailed explanation of NMR analyses.

from $\mathrm{CH}_{2}=\mathrm{THF}$ in a reaction catalyzed by glycine synthase (i.e., glycine cleavage enzyme) [35], which is encoded on the genome of $D$. formicoaceticum [21]. Thus, the formation of ${ }^{13} \mathrm{C}$-labeled glycine from $\mathrm{CH}_{2}=\mathrm{THF}$ can be explained in $D$. formicoaceticum cultures grown with ${ }^{13} \mathrm{C}$-DCM. The detection of the ${ }^{13} \mathrm{C}$-label in glycine provides additional evidence that DCM was metabolized via the Wood-Ljungdahl pathway. The ${ }^{1} \mathrm{H}$ and ${ }^{13} \mathrm{C}$ NMR analyses of ${ }^{13} \mathrm{C}$-DCM-grown culture $\mathrm{RM}$ and $D$. formicoaceticum agree with the GC-MS analysis (Figs. 2 and 3), and corroborate that ' $\mathrm{Ca}$. Dichloromethanomonas elyunquensis' and D. formicoaceticum metabolize DCM differently. This conclusion is supported by distinct dual carbon and chlorine isotope fractionation associated with DCM degradation in culture RM and D. formicoaceticum [24].

\section{Dependence of DCM degradation on $\mathrm{CO}_{2}$}

The anaerobic degradation of DCM by culture RM and D. formicoaceticum required the presence of $\mathrm{CO}_{2}$ in the medium (Fig. 4). No growth with DCM occurred in medium without $\mathrm{CO}_{2}$, and when $\mathrm{CO}_{2}$ was removed from growing cultures, DCM degradation stopped in both cultures (Fig. 4). The dependence of $\mathrm{CO}_{2}$ for DCM degradation by culture RM was observed in prior studies and attributed to a $\mathrm{CO}_{2}$ requirement of the DCM degrader ' $\mathrm{Ca}$.
Dichloromethanomonas elyunquensis' [15, 30]. Another possible explanation would be the strict $\mathrm{CO}_{2}$ requirement of the $\mathrm{H}_{2}$-consuming partner populations (i.e., hydrogenotrophic methanogens and homoacetogens) in culture RM. After removal of $\mathrm{CO}_{2}$, methanogenesis and acetogenesis activities in culture RM ceased and methane and acetate formation did not occur. The requirement for $\mathrm{CO}_{2}$ by the axenic culture $D$. formicoaceticum was explained by $\mathrm{CO}_{2}$-carbon assimilation into acetate via the Wood-Ljungdahl pathway, which agrees with the proposed fermentation model (viz., the carboxy group of acetate is derived from $\mathrm{CO}_{2}$ ) [18]. Thus, D. formicoaceticum is a mixotrophic bacterium and requires both the organic compound DCM and inorganic carbon (i.e., $\mathrm{CO}_{2}$ ) for growth. Mixotrophic growth lifestyles that depend on an inorganic carbon source (i.e., $\mathrm{CO}_{2}$ ) are common among methylotrophic homoacetogens and methanogens that utilize one-carbon (C1) compounds [29, 36, 37].

\section{DCM mineralization versus fermentation}

Taken together, the information obtained from the labeling experiments suggests that ' $\mathrm{Ca}$. Dichloromethanomonas elyunquensis' mineralized DCM completely to $\mathrm{CO}_{2}$ and $\mathrm{H}_{2}$ according to Eq. (3), and acetate in culture RM was exclusively derived from hydrogenotrophic partner populations performing $\mathrm{H}_{2} / \mathrm{CO}_{2}$ reductive acetogenesis (Fig. 5a). Mineralization is a biological process, in which organic 

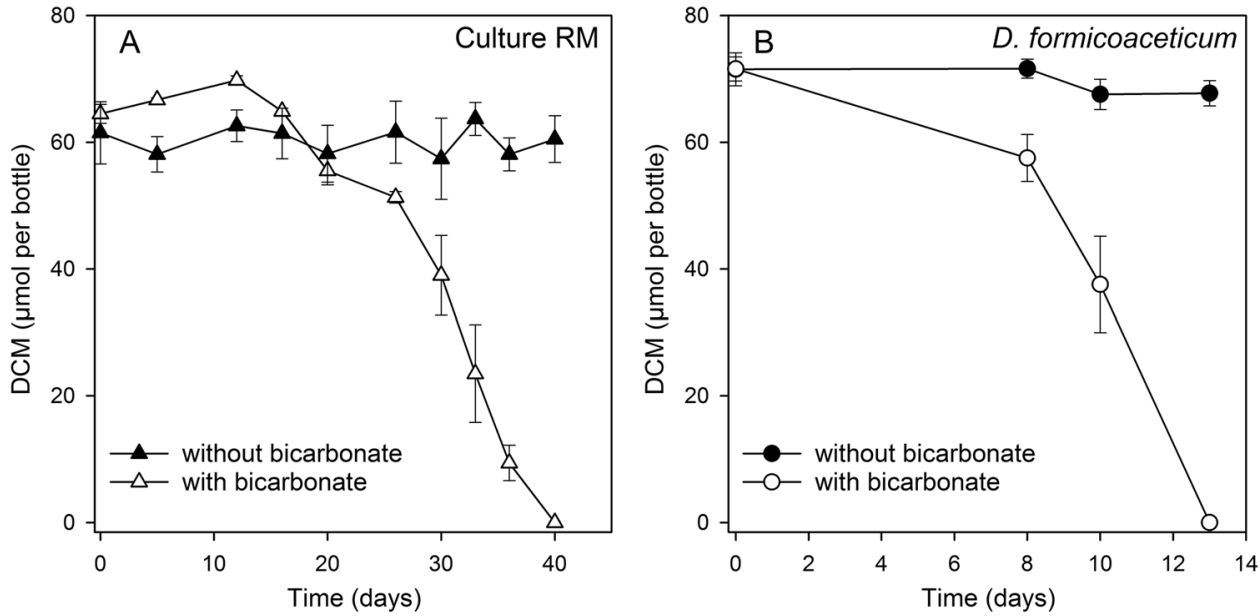

Fig. 4 DCM degradation requires the presence of bicarbonate/ $\mathbf{C O}_{2}$. In culture RM (a) and axenic D. formicoaceticum (b), DCM degradation only occurred in the presence of bicarbonate/ $\mathrm{CO}_{2}$. Experiments were performed in $\mathrm{CO}_{2}$-free HEPES-buffered mineral salt medium with $\mathrm{N}_{2}$ in the headspace. The positive control incubations used the same medium but received $10 \mathrm{mM}$ bicarbonate. Data shown represent the means \pm standard deviations $(n=3)$, and error bars represent standard deviations.
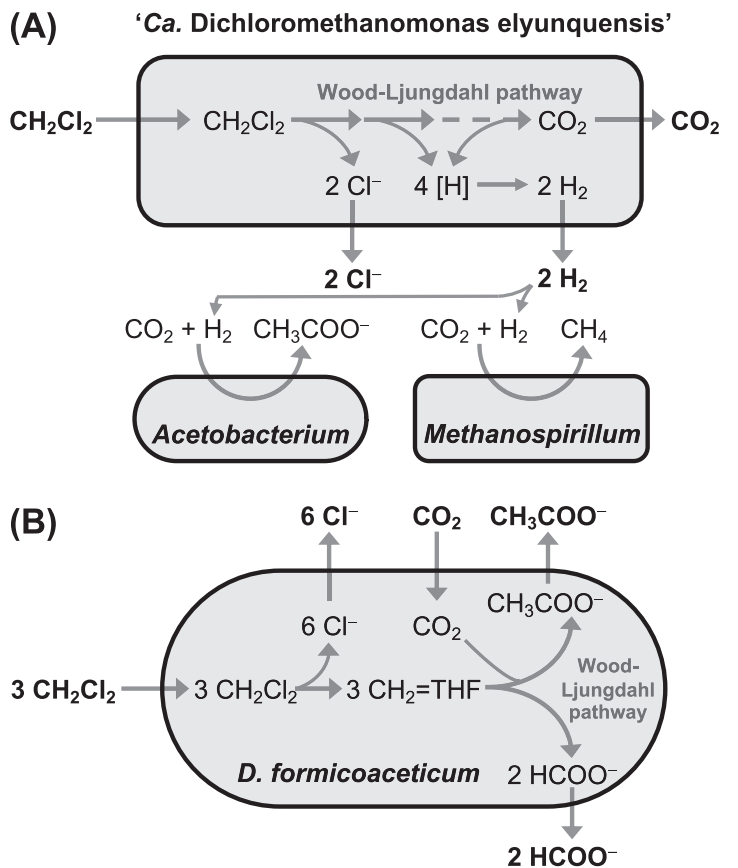

Fig. 5 Proposed scheme of complete DCM mineralization by ' $\mathrm{Ca}$. Dichloromethanomonas elyunquensis' versus DCM fermentation by $\boldsymbol{D}$. formicoaceticum. (a) Complete mineralization of DCM to $\mathrm{CO}_{2}$ by ' $\mathrm{Ca}$. Dichloromethanomonas elyunquensis' associated with the generation of $\mathrm{H}_{2}$, which supported growth of Acetobacterium spp. and Methanospirillum spp. to produce acetate and methane, respectively. (b) DCM fermentation to acetate and formate in axenic cultures of $D$. formicoaceticum. The initial dehalogenation reactions remain elusive, but DCM metabolism occurs via the Wood-Ljungdahl pathway.

compounds (e.g., DCM) are converted exclusively to inorganic end products, e.g., in this case to $\mathrm{CO}_{2}, \mathrm{H}_{2}$, and inorganic chloride. DCM mineralization to $\mathrm{CO}_{2}$ and $\mathrm{H}_{2}$ (Eq. (3)) is thermodynamically favorable with a Gibbs free energy change $\left(\Delta G^{\circ}\right)$ of $-188 \mathrm{~kJ} \mathrm{~mol}^{-1}$ of DCM under standard conditions $\left(\mathrm{H}_{2}=1 \mathrm{~atm}, \mathrm{pH}=7.0\right)$.

$$
\begin{array}{r}
\mathrm{CH}_{2} \mathrm{Cl}_{2}+2 \mathrm{H}_{2} \mathrm{O} \rightarrow \mathrm{CO}_{2}+2 \mathrm{H}_{2}+2 \mathrm{Cl}^{-}+2 \mathrm{H}^{+} \\
\Delta G^{\circ}=-188 \mathrm{~kJ} \mathrm{~mol}^{-1}
\end{array}
$$

Although thermodynamically feasible at high $\mathrm{H}_{2}$ partial pressures, DCM mineralization by ' $\mathrm{Ca}$. Dichloromethanomonas elyunquensis' required the presence of $\mathrm{H}_{2}$ consuming partner populations to consume $\mathrm{H}_{2}$. Growth experiments with exogenously added $\mathrm{H}_{2}$ demonstrated a strong inhibitory effect of $\mathrm{H}_{2}$ on DCM degradation [23, 32]. A possible explanation for the negative impact of $\mathrm{H}_{2}$ are the deleterious effects of $\mathrm{H}_{2}$ on the $\mathrm{H}_{2}$-evolving hydrogenase(s). Such product inhibition on $\mathrm{H}_{2}$-evolving hydrogenase(s) has been observed in previous studies [38-40] and exemplifies a situation where specific enzyme features supersede thermodynamics.

The ${ }^{13} \mathrm{CO}_{2}$ (about $1 \mathrm{mM}$ ) generated during ${ }^{13} \mathrm{C}-\mathrm{DCM}$ mineralization according to Eq. (3) was significantly diluted by the bulk bicarbonate buffer $(30 \mathrm{mM})$ in the medium, indicating that the ${ }^{13} \mathrm{C}$-labeled acetate produced from hydrogenotrophic ${ }^{13} \mathrm{CO}_{2}$ reduction by homoacetogens would be negligible. Consistently, no ${ }^{13} \mathrm{C}$-acetate was detected in RM cultures amended with ${ }^{13} \mathrm{C}-\mathrm{DCM}$ as a growth substrate by both GC-MS and NMR analyses. In contrast, ${ }^{13} \mathrm{C}$-labeled acetate and formate were detected in D. formicoaceticum cultures grown with ${ }^{13} \mathrm{C}-\mathrm{DCM}$, consistent with the fermentation pathway according to Eq. (1), and DCM was fermented to acetate and formate (Fig. 5b). Although the initial dechlorination mechanism(s) remains elusive, DCM metabolism by both ' $\mathrm{Ca}$. Dichloromethanomonas elyunquensis' and $D$. formicoaceticum occurs via the Wood-Ljungdahl pathway. 
In culture RM, methanogenesis and $\mathrm{H}_{2} / \mathrm{CO}_{2}$ reductive acetogenesis are two processes competing for reducing equivalents (i.e., $\mathrm{H}_{2}$ ) (Fig. 5a). From a thermodynamic perspective, hydrogenotrophic methanogenesis (Eq. (4)) is more favorable than $\mathrm{H}_{2} / \mathrm{CO}_{2}$ reductive acetogenesis (Eq. (5)) under standard conditions.

$$
\begin{gathered}
4 \mathrm{H}_{2}+\mathrm{CO}_{2} \rightarrow \mathrm{CH}_{4}+2 \mathrm{H}_{2} \mathrm{O} \Delta G^{\circ}=-130 \mathrm{~kJ} \mathrm{~mol}^{-1} \\
4 \mathrm{H}_{2}+2 \mathrm{CO}_{2} \rightarrow \mathrm{CH}_{3} \mathrm{COO}^{-}+\mathrm{H}^{+}+2 \mathrm{H}_{2} \mathrm{O} \\
\Delta G^{\prime \prime}=-95 \mathrm{~kJ} \mathrm{~mol}^{-1}
\end{gathered}
$$

Consistent with energetic considerations, more reducing equivalents were directed toward methane than acetate formation in DCM-grown RM cultures when methanogenesis was not inhibited by BES (Fig. 1a, and Table 1). Hydrogenotrophic methanogenesis did not completely outcompete $\mathrm{H}_{2} / \mathrm{CO}_{2}$ reductive acetogenesis and both processes co-occurred in culture RM over many generations in consecutive transfer cultures. Hydrogenotrophic $\mathrm{CO}_{2}$ reduction to methane and acetate is commonly observed in anoxic natural environments indicating that the thermodynamic advantage of hydrogenotrophic methanogenesis does not preclude $\mathrm{H}_{2} / \mathrm{CO}_{2}$ reductive acetogenesis from co-occurring [41, 42].

The Wood-Ljungdahl pathway is common in obligate anaerobic bacteria, but only specialized species can metabolize DCM via this pathway, indicating specific pathway modifications bestow the capability to grow with DCM. The experiments with ${ }^{13} \mathrm{C}$-labeled DCM conclusively demonstrated that $\mathrm{D}$. formicoaceticum and ' $\mathrm{Ca}$. Dichloromethanomonas elyunquensis' metabolize DCM differently, albeit both bacteria rely on the Wood-Ljungdahl pathway. D. formicoaceticum ferments DCM to formate and acetate whereas ' $\mathrm{Ca}$. Dichloromethanomonas elyunquensis' completely oxidizes DCM to $\mathrm{CO}_{2}$ with concomitant formation of $\mathrm{H}_{2}$ (Fig. 5). These findings indicate that specific modifications of the Wood-Ljungdahl pathway determine oxidative versus fermentative metabolism of DCM. The exact pathway differences in both bacteria are currently unknown but the observations highlight the flexibility of the Wood-Ljungdahl pathway, which is used in both the oxidative and reductive directions by various microbial groups [33]. The finding that nature has evolved at least two modifications of the Wood-Ljungdahl pathway for DCM metabolism can be seen as evidence that microbes adapted to DCM as a resource long before the anthropogenic introduction of DCM into the environment. Many chlorinated compounds, including DCM, occur naturally [3] and have been part of the biosphere for a long time.

Direct competition experiments between $D$. formicoaceticum and ' $\mathrm{Ca}$. Dichloromethanomonas elyunquensis'

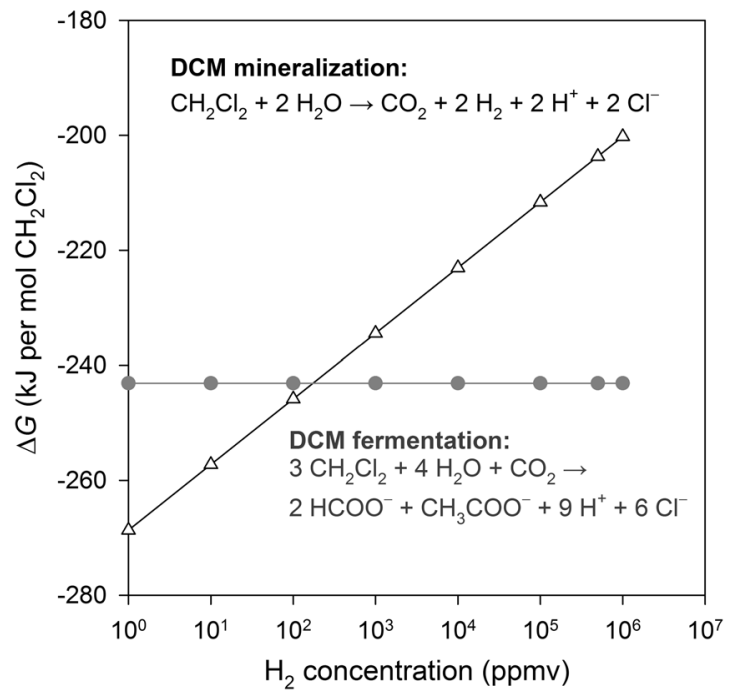

Fig. 6 The Gibbs free energy change $(\Delta G)$ associated with DCM mineralization and DCM fermentation at different $\mathrm{H}_{2}$ concentrations. Calculations were performed assuming $\left[\mathrm{CH}_{2} \mathrm{Cl}_{2}\right]=1 \mathrm{mM}$; $\left[\mathrm{CO}_{2}\right]=0.2 \mathrm{~atm} ; \quad\left[\mathrm{CH}_{3} \mathrm{COO}^{-}\right]=0.33 \mathrm{mM} ; \quad\left[\mathrm{HCOO}^{-}\right]=0.67 \mathrm{mM}$; $\left[\mathrm{Cl}^{-}\right]=33 \mathrm{mM} ; \mathrm{pH}=7.0$. Both of the processes are thermodynamically favorable with $\Delta G<0$. DCM mineralization becomes more favorable than DCM fermentation at $\mathrm{H}_{2}$ partial pressures below 100 ppmv.

have not been performed, and it is unclear if DCM fermentation and mineralization processes co-exist. Based on thermodynamic considerations, DCM fermentation (Eq. (1)) yields slightly more energy than DCM mineralization (Eq. (3)) under standard conditions $(\mathrm{pH}=7.0)$. DCM mineralization is a syntrophic process and relies on metabolic interactions between mutually dependent microbial partner populations. Elevated $\mathrm{H}_{2}$ partial pressures inhibit DCM mineralization and the $\mathrm{H}_{2}$ produced during DCM mineralization must be removed [23, 32]. If the $\mathrm{H}_{2}$ produced during DCM mineralization is consumed in hydrogenotrophic processes, the energy yield is substantially higher, and DCM mineralization becomes more favorable than DCM fermentation at $\mathrm{H}_{2}$ concentrations below $100 \mathrm{ppmv}\left(\sim 78 \mathrm{nM} \mathrm{H}_{2}\right)$ (Fig. 6).

The $\mathrm{H}_{2}$ generated during DCM metabolism in culture RM must be consumed by hydrogenotrophic partner populations performing $\mathrm{H}_{2} / \mathrm{CO}_{2}$ reductive acetogenesis or methanogenesis. Reported $\mathrm{H}_{2}$ consumption threshold concentrations for $\mathrm{H}_{2} / \mathrm{CO}_{2}$ reductive acetogenesis and hydrogenotrophic methanogenesis range from 430-4660 ppmv and 6-120 ppmv, respectively [43]. At $\mathrm{H}_{2}$ partial pressures near the reported lower $\mathrm{H}_{2}$ consumption threshold concentrations for $\mathrm{H}_{2} / \mathrm{CO}_{2}$ reductive acetogenesis and methanogenesis, the free energy change $\left(\Delta G^{\prime}\right)$ associated with DCM mineralization (Eq. (3)) increases to approximately -228 and $-246 \mathrm{~kJ} \mathrm{~mol}^{-1}$, respectively. Hydrogenotrophic organohalide-respiring bacteria consume $\mathrm{H}_{2}$ to even lower threshold concentrations of $<0.4 \mathrm{ppmv}$, resulting in even 
greater free energy change $\left(\Delta G^{\prime}\right)$ of about $-273 \mathrm{~kJ} \mathrm{~mol}^{-1}$ associated with DCM mineralization.

\section{Environmental implications}

The finding that bacteria metabolize DCM via distinct pathways has implications for carbon and electron flow in anoxic environments and for bioremediation. Fermentation of $1 \mathrm{~mol} \mathrm{DCM}$ yields $0.66 \mathrm{~mol}$ of formate, equivalent of $0.66 \mathrm{~mol}$ of $\mathrm{H}_{2}$ as formate and $\mathrm{H}_{2}$ pools can be considered energetically equivalent in anoxic environments [44]. More $\mathrm{H}_{2}$ is generated during complete oxidation of DCM by ' $\mathrm{Ca}$. Dichloromethanomonas elyunquensis', and 2 mol of $\mathrm{H}_{2}$ per mol of DCM are produced. The $\mathrm{H}_{2}$ produced can fuel different hydrogenotrophic processes, including methanogenesis, $\mathrm{H}_{2} / \mathrm{CO}_{2}$ reductive acetogenesis, and organohalide respiration. Reductive dechlorination of many priority groundwater contaminants such as chlorinated ethenes relies on $\mathrm{H}_{2}$ as electron donor $[45,46]$, and in mixed contaminant plumes, DCM mineralization and associated $\mathrm{H}_{2}$ formation could sustain reductive dechlorination processes. Hydrogenotrophic organohalide-respiring bacteria would be ideal partner populations for syntrophic DCM mineralization because they consume $\mathrm{H}_{2}$ to very low partial pressures [43]. Obviously important is the amount of $\mathrm{H}_{2}$ generated during DCM degradation and tools to distinguish fermentation versus mineralization would be desirable, but tractable biomarkers have yet to be identified. Zero valent iron walls have been applied for in situ treatment of contaminants including carbon tetrachloride and chloroform [47, 48]. Such treatment leads to the formation of $\mathrm{H}_{2}$ and DCM. Based on the outcomes of this study, the prediction would be that bacteria employing the fermentative pathway would dominate as long as the $\mathrm{H}_{2}$ partial pressures exceed 100 ppmv.

Acetate is a central intermediate during the degradation of organic matter in the anoxic environments [49, 50]. For example, the fermentation of $\mathrm{C} 1$ compounds, including DCM, chloromethane, methanol, and carbon monoxide (CO), via the Wood-Ljungdahl pathway leads to acetate formation [51-53]. Acetate can be oxidized to $\mathrm{CO}_{2}$ if hydrogenotrophic partner populations consume the $\mathrm{H}_{2}$ generated in the oxidation reaction (i.e., syntrophic acetate oxidation), or acetate is fermented to $\mathrm{CO}_{2}$ and methane by acetoclastic methanogens; however, both of the pathways leading to acetate mineralization are thermodynamically challenging reactions and require specialized microorganisms $[49,54,55]$. Our study demonstrates that complete mineralization of DCM to inorganic products, and possibly of other $\mathrm{C} 1$ compounds (e.g., methanol [56]), by a single taxon can occur in cooperative interactions with hydrogenotrophic community members. The $\mathrm{H}_{2}$ partial pressure is a controlling parameter over $\mathrm{C} 1$ compound mineralization versus fermentation pathways with consequences for microbial community structure and carbon and electron flow in anoxic environments where DCM is introduced through natural production processes or anthropogenic activities.

Culture RM grows with DCM as the sole energy source in defined, completely synthetic, bicarbonate-buffered basal salt medium, and has undergone at least 80 consecutive transfers under these conditions over the past 7 years. Microbial community analysis based on 16S rRNA gene amplicon sequencing and metagenome analysis revealed that culture RM still harbors a very diverse community $[19,23]$. It is astonishing that a simple chlorinated $\mathrm{C} 1$ compound (i.e., DCM) can sustain such a diverse community under strictly anoxic conditions without any external electron acceptors. A question of interest to microbial ecologist are the intricate organismal relationships that allow the sharing of energy contained in a chlorinated $\mathrm{C} 1$ compound (i.e., DCM) among community members. Unraveling how DCM sustains a diverse community could reveal new insights into the mechanisms that drive interdependent, syntrophic community development.

Acknowledgements This work was supported by The Chemours Company and the Strategic Environmental Research and Development Program (SERDP) under project ER-2312.

\section{Compliance with ethical standards}

Conflict of interest The authors declare no conflict of interest.

Publisher's note Springer Nature remains neutral with regard to jurisdictional claims in published maps and institutional affiliations.

\section{References}

1. McCulloch A, Midgley PM. The production and global distribution of emissions of trichloroethene, tetrachloroethene and dichloromethane over the period 1988-1992. Atmos Environ. 1996;30:601-8.

2. Keene WC, Khalil MAK, Erickson DJ III, McCulloch A, Graedel TE, Lobert JM, et al. Composite global emissions of reactive chlorine from anthropogenic and natural sources: Reactive chlorine emissions inventory. J Geophys Res. 1999;104:8429-40.

3. Gribble GW Naturally occurring organohalogen compounds-a comprehensive update. In: Kinghorn AD, Falk H, Kobayashi J (eds). Progress in the Chemistry of Organic Natural Products. Springer Verlag, Vienna, 2010, Vol. 91, pp 12-13.

4. Kolusu SR, Schlünzen KH, Grawe D, Seifert R. Determination of chloromethane and dichloromethane in a tropical terrestrial mangrove forest in Brazil by measurements and modelling. Atmos Environ. 2018;173:185-97.

5. Kolusu SR, Schlünzen KH, Grawe D, Seifert R. Chloromethane and dichloromethane in the tropical Atlantic Ocean. Atmos Environ. 2017;150:417-24. 
6. Leedham Elvidge EC, Oram DE, Laube JC, Baker AK, Montzka $\mathrm{SA}$, Humphrey $\mathrm{S}$, et al. Increasing concentrations of dichloromethane, $\mathrm{CH}_{2} \mathrm{Cl}_{2}$, inferred from CARIBIC air samples collected 1998-2012. Atmos Chem Phys. 2015;15:1939-58.

7. Hossaini R, Chipperfield MP, Saiz-Lopez A, Harrison JJ, von Glasow R, Sommariva R, et al. Growth in stratospheric chlorine from short-lived chemicals not controlled by the Montreal Protocol. Geophys Res Lett. 2015;42:4573-80.

8. Moran MJ, Zogorski JS, Squillace PJ. Chlorinated solvents in groundwater of the United States. Environ Sci Technol. 2007;41:74-81.

9. Hossaini R, Chipperfield MP, Montzka SA, Leeson AA, Dhomse SS, Pyle JA. The increasing threat to stratospheric ozone from dichloromethane. Nat Commun. 2017;8:15962.

10. Leisinger T, Bader R, Hermann R, Schmid-Appert M, Vuilleumier $\mathrm{S}$. Microbes, enzymes and genes involved in dichloromethane utilization. Biodegradation. 1994;5:237-48.

11. Vuilleumier S, Pagni M. The elusive roles of bacterial glutathione $S$-transferases: new lessons from genomes. Appl Microbiol Biotechnol. 2002;58:138-46.

12. Freedman DL, Gossett JM. Biodegradation of dichloromethane and its utilization as a growth substrate under methanogenic conditions. Appl Environ Microbiol. 1991;57:2847-57.

13. Stromeyer SA, Winkelbauer W, Kohler H, Cook AM, Leisinger T. Dichloromethane utilized by an anaerobic mixed culture: acetogenesis and methanogenesis. Biodegradation. 1991;2:129-37.

14. Mägli A, Rainey FA, Leisinger T. Acetogenesis from dichloromethane by a two-component mixed culture comprising a novel bacterium. Appl Environ Microbiol. 1995;61:2943-9.

15. Justicia-Leon SD, Ritalahti KM, Mack EE, Löffler FE. Dichloromethane fermentation by a Dehalobacter sp. in an enrichment culture derived from pristine river sediment. Appl Environ Microbiol. 2012;78:1288-91.

16. Trueba-Santiso A, Parlade E, Rosell M, Lliros M, Mortan SH, Martinez-Alonso M, et al. Molecular and carbon isotopic characterization of an anaerobic stable enrichment culture containing Dehalobacterium sp. during dichloromethane fermentation. Sci Total Environ. 2017;581-582:640-8.

17. Mägli A, Wendt M, Leisinger T. Isolation and characterization of Dehalobacterium formicoaceticum gen. nov. sp. nov., a strictly anaerobic bacterium utilizing dichloromethane as source of carbon and energy. Arch Microbiol. 1996;166:101-8.

18. Mägli A, Messmer M, Leisinger T. Metabolism of dichloromethane by the strict anaerobe Dehalobacterium formicoaceticum. Appl Environ Microbiol. 1998;64:646-50.

19. Kleindienst S, Higgins SA, Tsementzi D, Chen G, Konstantinidis KT, Mack EE, et al. 'Candidatus Dichloromethanomonas elyunquensis' gen. nov., sp. nov., a dichloromethane-degrading anaerobe of the Peptococcaceae family. Syst Appl Microbiol. 2017;40:150-9.

20. Kleindienst S, Higgins SA, Tsementzi D, Konstantinidis KT, Mack EE, Löffler FE. Draft genome sequence of a strictly anaerobic dichloromethane-degrading bacterium. Genome Announc. 2016;4:e0037-16.

21. Chen G, Murdoch RW, Mack EE, Seger ES, Löffler FE. Complete genome sequence of Dehalobacterium formicoaceticum strain DMC, a strictly anaerobic dichloromethane-degrading bacterium. Genome Announc. 2017;5:e00897-17.

22. Kleindienst S, Chourey K, Chen G, Murdoch RW, Higgins SA, Iyer R, et al. Proteogenomics reveals novel reductive dehalogenases and methyltransferases expressed during anaerobic dichloromethane metabolism. Appl Environ Microbiol. 2019;85: e02768-18.

23. Chen G, Kleindienst S, Griffiths DR, Mack EE, Seger ES, Löffler FE. Mutualistic interaction between dichloromethane- and chloromethane-degrading bacteria in an anaerobic mixed culture. Environ Microbiol. 2017;19:4784-96.

24. Chen G, Shouakar-Stash O, Phillips E, Justicia-Leon SD, Gilevska T, Sherwood Lollar B, et al. Dual carbon-chlorine isotope analysis indicates distinct anaerobic dichloromethane degradation pathways in two members of Peptococcaceae. Environ Sci Technol. 2018;52:8607-16.

25. Löffler FE, Sanford RA, Ritalahti KM. Enrichment, cultivation, and detection of reductively dechlorinating bacteria. Methods Enzymol. 2005;397:77-111.

26. Ritalahti KM, Amos BK, Sung Y, Wu Q, Koenigsberg SS, Löffler FE. Quantitative PCR targeting 16S rRNA and reductive dehalogenase genes simultaneously monitors multiple Dehalococcoides strains. Appl Environ Microbiol. 2006;72:2765-74.

27. Zheng X, Qiu Y, Zhong W, Baxter S, Su M, Li Q, et al. A targeted metabolomic protocol for short-chain fatty acids and branchedchain amino acids. Metabolomics. 2013;9:818-27.

28. Smidt H, De Vos WM. Anaerobic microbial dehalogenation. Annu Rev Microbiol. 2004;58:43-73.

29. Schuchmann K, Müller V. Energetics and application of heterotrophy in acetogenic bacteria. Appl Environ Microbiol. 2016;82:4056-69.

30. Justicia-Leon SD, Higgins S, Mack EE, Griffiths DR, Tang S, Edwards EA, et al. Bioaugmentation with distinct Dehalobacter strains achieves chloroform detoxification in microcosms. Environ Sci Technol. 2014;48:1851-8.

31. Maymó-Gatell X, Nijenhuis I, Zinder SH. Reductive dechlorination of cis-1,2-dichloroethene and vinyl chloride by "Dehalococcoides ethenogenes". Environ Sci Technol. 2001;35:516-21.

32. Lee M, Low A, Zemb O, Koenig J, Michaelsen A, Manefield M. Complete chloroform dechlorination by organochlorine respiration and fermentation. Environ Microbiol. 2012;14:883-94.

33. Ragsdale SW, Pierce E. Acetogenesis and the Wood-Ljungdahl pathway of $\mathrm{CO}_{2}$ fixation. Biochim Biophys Acta. 2008; 1784:1873-98.

34. Borrel G, Adam PS, Gribaldo S. Methanogenesis and the Wood-Ljungdahl pathway: an ancient, versatile, and fragile association. Genome Biol Evol. 2016;8:1706-11.

35. Gariboldi RT, Drake HL. Glycine synthase of the purinolytic bacterium, Clostridium acidiurici. purification of the glycine- $\mathrm{CO}_{2}$ exchange system. J Biol Chem. 1984;259:6085-9.

36. Jones SW, Fast AG, Carlson ED, Wiedel CA, Au J, Antoniewicz $\mathrm{MR}$, et al. $\mathrm{CO}_{2}$ fixation by anaerobic non-photosynthetic mixotrophy for improved carbon conversion. Nat Commun. 2016;7:12800.

37. Yin X, Wu W, Maeke M, Richter-Heitmann T, Kulkarni AC, Oni $\mathrm{OE}$, et al. $\mathrm{CO}_{2}$ conversion to methane and biomass in obligate methylotrophic methanogens in marine sediments. ISME J. 2019;13:2107-19.

38. Fourmond V, Baffert C, Sybirna K, Dementin S, AbouHamdan A, Meynial-Salles I, et al. The mechanism of inhibition by $\mathrm{H}_{2}$ of $\mathrm{H}_{2}$-evolution by hydrogenases. Chem Commun. 2013;49:6840-2.

39. Shafaat HS, Rüdiger O, Ogata H, Lubitz W. [NiFe] hydrogenases: a common active site for hydrogen metabolism under diverse conditions. Biochim Biophys Acta. 2013;1827:986-1002.

40. Lubitz W, Ogata H, Rudiger O, Reijerse E. Hydrogenases. Chem Rev. 2014;114:4081-148.

41. Kotelnikova S, Pedersen K. Evidence for methanogenic Archaea and homoacetogenic Bacteria in deep granitic rock aquifers. FEMS Microbiol Rev. 1997;20:339-49.

42. Lever M. Acetogenesis in the energy-starved deep biosphere-a paradox? Front Microbiol. 2012;2:284.

43. Löffler FE, Tiedje JM, Sanford RA. Fraction of electrons consumed in electron acceptor reduction and hydrogen thresholds as 
indicators of halorespiratory physiology. Appl Environ Microbiol. 1999;65:4049-56.

44. Schink B, Montag D, Keller A, Müller N. Hydrogen or formate: Alternative key players in methanogenic degradation. Environ Microbiol Rep. 2017;9:189-202.

45. Löffler FE, Yan J, Ritalahti KM, Adrian L, Edwards EA, Konstantinidis KT, et al. Dehalococcoides mccartyi gen. nov., sp nov., obligately organohalide-respiring anaerobic bacteria relevant to halogen cycling and bioremediation, belong to a novel bacterial class, Dehalococcoidia classis nov., order Dehalococcoidales ord. nov and family Dehalococcoidaceae fam. nov., within the phylum Chloroflexi. Int J Syst Evol Microbiol. 2013;63:625-35.

46. Atashgahi S, Lu Y, Smidt H. Overview of known organohaliderespiring bacteria-phylogenetic diversity and environmental distribution. In: Adrian, L; Löffler, FE, (eds). Organohaliderespiring bacteria. Springer Verlag, Berlin, Heidelberg, 2016, p. 63-105.

47. Lee M, Wells E, Wong YK, Koenig J, Adrian L, Richnow HH, et al. Relative contributions of Dehalobacter and zerovalent iron in the degradation of chlorinated methanes. Environ Sci Technol. 2015;49:4481-9.

48. Wang S, Chen S, Wang Y, Low A, Lu Q, Qiu R. Integration of organohalide-respiring bacteria and nanoscale zero-valent iron
(Bio-nZVI-RD): a perfect marriage for the remediation of organohalide pollutants? Biotechnol Adv. 2016;34:1384-95.

49. Schink B. Energetics of syntrophic cooperation in methanogenic degradation. Microbiol Mol Biol Rev. 1997;61:262-80.

50. Beulig F, Røy H, Glombitza C, Jørgensen BB. Control on rate and pathway of anaerobic organic carbon degradation in the seabed. Proc Natl Acad Sci USA. 2018;115:367-72.

51. Meßmer M, Wohlfarth G, Diekert G. Methyl chloride metabolism of the strictly anaerobic, methyl chloride-utilizing homoacetogen Strain MC. Arch Microbiol. 1993;160:383-7.

52. Ragsdale SW. Life with carbon monoxide. Crit Rev Biochem Mol Biol. 2004;39:165-95.

53. Kremp F, Poehlein A, Daniel R, Müller V. Methanol metabolism in the acetogenic bacterium Acetobacterium woodii. Environ Microbiol. 2018;20:4369-84.

54. Morris BE, Henneberger R, Huber $H$, Moissl-Eichinger $C$. Microbial syntrophy: interaction for the common good. FEMS Microbiol Rev. 2013;37:384-406.

55. Westerholm M, Dolfing J, Schnürer A. Growth characteristics and thermodynamics of syntrophic acetate oxidizers. Environ Sci Technol. 2019;53:5512-20.

56. Weijma J, Stams AJ. Methanol conversion in high-rate anaerobic reactors. Water Sci Technol. 2001;44:7-14. 